\title{
Analisis Kompetensi Amilin dalam Peningkatan Penerimaan Dana Zakat Infaq Shadaqah di Bazna Kabupaten Bandung
}

\author{
Adila Qanita Dini, Zaini Abdul Malik, Yayat Rahmat H \\ Program Studi Hukum Ekonomi \\ Syariah, Fakultas Syariah, Universitas Islam Bandung \\ Jl. Tamansari No. 140116 \\ adilaqdini@gmail.com,za.abuhibban@gmail.com,yayatrahmathidayat@unisba.ac.id
}

\begin{abstract}
Abstarct-Public trust in an amil zakat institution is very important and decisive. The demand for professionalism of an amil zakat today certainly determines the optimal management of zakat by an amil zakat body. However, the emergence of an attitude of distrust of zakat organizers who in this case such as the Bandung District BAZNAS as an indication of the values of professionalism has not been implemented yet. Based on the explanation on the background of the problem above, the writer formulated several problem formulations as follows: To find out the competence of amiline according to Islam, to find out the level of amiline competence in managing zakat infaq shadaqah in BAZNAS Bandung Regency, and to find out amiline competence in managing zakat infaq shadaqah in BAZNAS Regency of Bandung. The research method used in the preparation of this study is to use qualitative analysis that is analyzing amiline competence in BAZNAS Bandung Regency in increasing the receipt of zakat infaq shadaqah funds in terms of the perspective of Islamic work ethic values. The results of this study are that Amilin's competence according to Islam is the amiline requirements which must be in accordance with the characteristics of the Prophet Muhammad SAW namely shiddiq, fathonah, amanah and tabligh (NATURE) and administrative requirements set out in Law Number 23 Year 2011 Regarding the Management of Zakat as well as regulations others prevailing in Indonesia, amiline competence in managing zakat infaq shadaqah at the Bandung District BAZNAS has increased along with HR planning programs conducted through organizing training for amilines, and analysis of amiline competence in managing zakat infaq shadaqah and in accordance with amiline requirements which must be in accordance with the characteristics of Rasulullah SAW namely shiddiq, fathonah, amanah and tabligh (SIFAT) as well as administrative requirements regulated in Law Number 23 of 2011 concerning Management of Zakat.
\end{abstract}

Keywords-Zakat, Amilin, Competence and HR Management.

Abstraks-Kepercayaan publik pada suatu institusi lembaga amil zakat sangatlah penting dan menentukan. Tuntutan profesionalisme seorang amil zakat pada masa sekarang tentu menjadi penentu optimalnya pengelolaan zakat oleh suatu badan amil zakat. Akan tetapi, munculnya sikap kurang percaya terhadap amil para penyelenggara zakat yang dalam hal ini seperti BAZNAS Kabupaten Bandung sebagai indikasi belum diterapkannya nilai-nilai profesionalisme amilin. Tujuan penelitian ini adalah : Untuk mengetahui amilin menurut Islam, untuk mengetahui tingkat kompetensi amilin dalam mengelola zakat infaq shadaqah di BAZNAS Kabupaten Bandung, dan untuk mengetahui analisis kompetensi amilin dalam mengelola zakat infaq shadaqah di BAZNAS Kabupaten Bandung. Metode penelitian yang digunakan dalam penyusunan penelitian ini adalah dengan menggunakan analisis kualitatif yaitu melakukan analisis kompetensi amilin di BAZNAS Kabupaten Bandung dalam peningkatan penerimaan dana zakat infaq shadaqah ditinjau dari perspektif nilai-nilai etos kerja Islam. Hasil dari penelitian ini adalah kompetensi Amilin menurut Islam adalah persyaratan amilin yang sesuai dengan sifat-sifat Rasulullah SAW yaitu shiddiq, fathonah, amanah dan tabligh (SIFAT) dan persyaratan administrif yang diatur dalam UU Nomor 23 Tahun 2011 Tentang Pengelolaan Zakat serta peraturan-peraturan lain yang berlaku di Indonesia, kompetensi amilin dalam mengelola zakat infaq shadaqah di BAZNAS Kabupaten Bandung mengalami peningkatan seiring dengan program perencanaan SDM yang dilakukan melalui penyelenggaraan pelatihan bagi para amilin, sertaAnalisis kompetensi amilin dalam mengelola zakat infaq shadaqah dan telah sesuai dengan persyaratan amilin yang harus sesuai dengan sifat-sifat Rasulullah SAW yaitu shiddiq, fathonah, amanah dan tabligh (SIFAT) serta persyaratan administrtif yang diatur dalam UU Nomor 23 Tahun 2011 Tentang Pengelolaan Zakat.

Kata Kunci-Zakat, Amilin, Kompetensi dan Manajemen SDM.

\section{PENDAHULUAN}

\section{A. Latar Belakang Masalah}

Setiap kegiatan pengelolaan zakat pada lembaga amilin zakat tidak lepas dari aspek manajemen. Dalam hal ini terdapat 4 fungsi manajemen yang menjadi tolak ukur keberhasilan BAZNAS sebagai lembaga amil zakat dalam pengelolaan zakat produktifnya yang meliputi perencanaan (planning), pengorganisasian / staffing (organizingi, pelaksanaan (actuating) dan pengawasan (controling). Pada perkembangannya, kegiatan operasional BAZNAS mengelami berbagai permasalahan dan kendala seiring dengan dinamika zaman terutama terkait peranananya kepada masayarakat.

Salah satu aspek kajian dalam manajemen adalah pengelolaan sumber daya manusia (SDM), karena 
pengelolaan Sumber Daya Manusia (SDM) merupakan hal yang terkait upaya dalam pencapaian tujuan suatu organisasi atau lembaga. Umumnya pimpinan perusahaan mengharapkan kinerja yang baik dari masing-masing amilin dalam mengerjakan tugas-tugas yang diberikan oleh perusahaan. Perusahaan menyadari bahwa Sumber Daya Manusia (SDM) merupakan modal dasar dalam proses pembangunan perusahaan. Oleh karena itu pemantauan kinerja terhadap Sumber Daya Manusia (SDM) sangat penting agar tujuan yang di tetapkan oleh perusahaan tercapai secara maksimal.

Terkait hal di atas, maka Badan Amil Zakat Nasional (BAZNAS) Kabupaten Bandung harus dapat mempersiapkan sumber daya manusia yang unggul bagi para amilinnya. Dalam hal ini, amilin BAZNAS harus benar-benar berkualitas dan profesional yang sangat dapat mempengaruhi kinerja lembaga untuk mencapai tujuan organisasi. BAZNAS dapat menetapkan sasaran kerja dan standar kinerja yang harus dicapai serta menilai hasil-hasil yang dicapai pada akhir periode tertentu dalam hal pengelolaan zakat.

Indikator kompetensi amilin setidaknya harus mencakup 4 hal yaitu agamanya, intelektualitasnya, integritasnya dan kemampuannya dalam mengelola zakat. Selain dari ketentuan umum yang diuraikan di atas, untuk menilai kinerja amilin di lembaga pengelola zakat sperti BAZNAS atau LAZ, maka diperlukan indikator yang pasti secara professional untuk menentukan kualifikasi amilin. Dengan demikian, maka kompetensi tersebut diharapkan mampu mengoptimalkan kinerja amilin karena hal ini sangat menentukan performa kinerja lembaga amil zakat atau Badan Amil Zakat secara keseluruhan.

\section{B. Tujuan Penelitan}

Tujuan penelitian ini untuk memperoleh jawaban dari permasalahan yang telah dirumuskan. Adapun tujuan dalam penelitian ini adalah antara lain :

1. Untuk mengetahui kompetensi amilin menurut Islam.

2. Untuk mengetahui tingkat kompetensi amilin dalam mengelola zakat infaq shadaqah di BAZNAS Kabupaten Bandung.

3. Untuk mengetahui kompetensi amilin dalam mengelola zakat infaq shadaqah di BAZNAS Kabupaten BandungLandasan Teori

\section{LANDASAN TEORI}

\section{A. Tinjauan Umum Kompetensi}

Kompetensi adalah suatu kemampuan untuk melaksanakan atau melakukan suatu pekerjaan atau tugas yang dilandasi atas keterampilan dan pengetahuan serta didukung oleh sikap kerja yang dituntut oleh pekerjaan tersebut. ${ }^{1}$ Dengan demikian, menurut Wibowo kompetensi menunjukkan keterampilan atau pengetahuan yang dicirikan oleh profesionalisme dalam suatu bidang tertentu sebagai sesuatu yang terpenting, sebagai unggulan bidang tertentu, dengan indikatornya adalah ${ }^{2}$ :

\section{Pengetahuan (Knowledge)}

Pengetahuan yang berkaitan dengan pekerjaan meliputi :

a. Mengetahui dan memahami pengetahuan dibidang masing-masing.

b. Mengetahui pengetahuan yang berhubungan dengan peraturan, prosedur, teknik yang baru dalam institusi pemerintahan.

\section{Keterampilan (Skill)}

Keterampilan individu meliputi:

a. Kemampuan dalam berkomunikasi dengan baik secara tulisan.

b. Kemampuan berkomunikasi dengan jelas secara lisan.

3. Sikap (Attitude)

Sikap individu, meliputi :

a. Memiliki kemampuan dalam berkomunikasi dalam berkreativitas dalam bekerja.

b. Adanya semangat kerja yang tinggi.

c.

Kompetensi merupakan karakteristik mendasar yang dimiliki seseorang yang berpengaruh langsung atau dapat memprediksikan kinerja yang sangat baik. Dalam ajaran Islam, kompetensi merupakan unsur kemaslahatan yang dapat menentukan baiknya hasil pekerjaan oleh seseorang karena sesuai dengan kompetensi yang dimilikinya. Hal ini sebagaimana yang disabdakan Rasulullah SAW dalam hadits sebagai berikut :

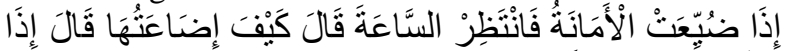

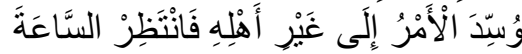

Apabila sudah hilang amanah maka tunggulah terjadinya kiamat". Orang itu bertanya: "Bagaimana hilangnya amanat itu?" Nabi shallallahu 'alaihi wasallam menjawab: "Jika urusan diserahkan bukan kepada ahlinya, maka akan tunggulah terjadinya kiamat". ${ }^{3}$

Hadits di atas menunjukkan bahwa jika suatu pekerjaan dikerjakan oleh seseorang yang tidak memiliki kompetensi pada bidang pekerjaan tersebut, maka hasilnya adalah kehancuran atau tidak berhasil sesuai dengan target yang sudah ditentukan. Kompetensi dalam Islam bahkan dianjurkan dimana manusia harus memiliki kompetitif dalam hal kebaikan dan profesionalisme ketika bekerja. ${ }^{4}$ Hal ini sebagaimana dengan firman Allah SWT dalam Q.S Al Baqarah ayat 148 sebagai berikut :

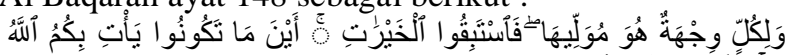

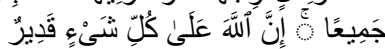


Dan bagi tiap-tiap umat ada kiblatnya (sendiri) yang ia menghadap kepadanya. Maka berlomba-lombalah (dalam membuat) kebaikan. Di mana saja kamu berada pasti Allah akan mengumpulkan kamu sekalian (pada hari kiamat). Sesungguhnya Allah Maha Kuasa atas segala sesuatu. $^{5}$

Berdasarkan uraian di atas, maka dapat dikatakan bahwa kompetensi merupakan dimensi perilaku yang berada di belakang di belakang kinerja kompeten. Sering dinamakan kompetensi perilaku karena dimaksudkan untuk menjelaskan bagaimana perilaku karena dimaksudkan untuk menjelaskan bagaimana orang berprilaku ketika mereka menjalankan peranya dengan baik, itu pendapat dari Armstrong dan Baron. ${ }^{6}$ Kompetensi erat kaitannya dengan kajian sumber daya manusia karena kompetensi melekat pada potensi diri seseorang.

Manajemen sumber daya manusia merupakan bidang manajemen yang menitikberatkan pada salah satu faktor yaitu faktor manusia. Faktor manusia sangatlah penting dan menentukan bagi suatu perusahaan di dalam melakukan segala kegiatan usaha. Faktor manusia banyak berperan di dalam mengendalikan perusahaan kemanapun arah yang akan dituju. Maju mundurnya perusahaan tergantung bagaimana faktor manusia itu mengelolanya, mengarahkan serta mengendalikannya. ${ }^{7}$

\section{B. Kompetensi Amil Zakat}

Amilin zakat dalam konteks pekerjaan mengelola zakat tentu dapat dikatakan sebagai profesi karena memiliki spesifikasi pekerjaan yang khas serta tuntutan kompetensi berdasarkan ketentuan agama dan undangundang yang berlaku di Indonesia. Dalam hal ini, amil zakat perlu disertifikasi karena proses zakat melingkupi tiga hal yaitu penghimpunan, pengelolaan yang harus akuntabilel, transparan, dan menjalankannya dengan baik serta penyaluran dan pendayagunaan. Karakter penyaluran zakat itu sendiri harus memiliki standar kerja, mulai dari etikanya, kompetensi, faktor integritas, dan lain-lain sebagai jaminan para amil ini bekerja dengan benar. ${ }^{8}$

Secara bahasa, istilah amil berasal dari kata 'amila ya'malu (عمِلَ - يَعْمَلُ ), yang bermakna mengerjakan atau melakukan sesuatu. Kata amil (عامل) adalah ism fail yang bermakna pelaku dari suatu pekerjaan. Maka kata amil bermakna orang yang mengerjakan sesuatu. ${ }^{9}$ Adapun secara istilah, amil zakat dalam disiplin ilmu fiqih zakat bermakna :

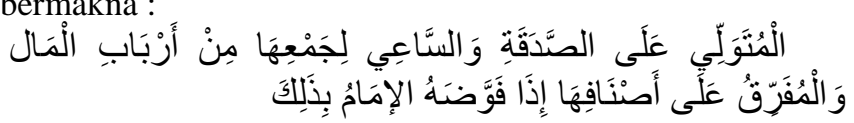

Orang yang diberi kewenangan untuk mengurus shadaqah (zakat) dan bertugas untuk berjalan dalam rangka mengumpulkannya dari para pemilik harta, dan yang mendistribusikannya kepada pihak yang berhak bila diberi kuasa oleh penguasa. 10

Istilah amil zakat ini punya beberapa istilah lain yang sama, diantaranya : su'aat lli jibayatizzakah ( سعاة لجباية الزكاة), yang artinya adalah orang yang berkeliling untuk mengumpulkan zakat. Menurut ketentuan MUI dalam Fatwa MUI Nomor 8 Tahun 2011 tentang Amil Zakat Pasal 1, yang dimaksud Amil zakat adalah ${ }^{11}$ :

1. Seseorang atau sekelompok orang yang diangkat oleh Pemerintah untuk mengelola pelaksanaan ibadah zakat; atau

2. Seseorang atau sekelompok orang yang dibentuk oleh masyarakat dan disahkan oleh Pemerintah untuk mengelola pelaksanaan ibadah zakat.

Dalam ketentuan Fatwa MUI Nomor 8 Tahun 2011 Tentang Amilin Zakat Pasal 2, disebutkan bahwa syaratsyarat amilin zakat adalah sebagai berikut 12 :

1. Beragama Islam;

2. Mukallaf (berakal dan baligh);

3. Amanah;

4. Memiliki ilmu pengetahuan tentang hukum-hukum zakat dan hal lain yang terkait dengan tugas Amil zakat.

\section{Hasil PENELITIAN DAN ANALISA PEMBAhasan}

Kompetensi amilin di BAZNAS Kabupaten Bandung terdiri dari dua dimensi kualifikasi.Pertama, kualifikasi dari sisi administratif atau kualifikasi formil. Kedua, dari sisi kualitas personal. Dari sisi kualifikasi formil, BAZNAS Kabupaten Pandelang memberikan syarat kualifikasi amilin berdasarkan Fatwa MUI Nomor 8 Tahun 2011 Tentang Amilin Zakat Pasal 2, disebutkan bahwa syarat-syarat amilin zakat adalah sebagai berikut :

1. Beragama Islam;

2. Mukallaf (berakal dan baligh);

3. Amanah;

4. Memiliki ilmu pengetahuan tentang hukum-hukum zakat dan hal lain yang terkait dengan tugas Amil zakat.

Sedangkan dari sisi kualifikasi non formal, BAZNAS Kabupaten Bandung yang mengangkat dan melantik para amilin mewajibkan para amilin untuk bekerja berkewajiban melaksanakan pengawasan untuk meneladani sunnah Nabi SAW dalam melakukan tugas kontrol terhadap para amil zakat. Seorang amil zakat di BAZNAS Kabupaten Bandung harus jujur dan bertanggung jawab terhadap harta zakat yang ada di tangannya dan bertanggung jawab mengganti kerusakan 
yang terjadi akibat kecerobohan dan kelalaiannya.

Terkait dua dimensi kualifikasi amilin di atas, maka jajaran manajemen BAZNAS sebagaimana yang dituturkan oleh Wakil Ketua I BAZNAS Bapak Drs. H. M. Acang memberikan pengarahan bahwa para petugas zakat harus mempunyai etika keislaman secara umum. Misalnya, penyantun dan ramah kepada para wajib zakat (muzaki) dan selalu mendoakan mereka.Begitu juga terhadap para mustahik, mereka mesti dapat menjelaskan kepentingan zakat dalam menciptakan solidaritas sosial.Selain itu, agar menyalurkan zakat sesegera mungkin kepada para mustahik. Untuk memenuhi target pengarahan yang dilakukan manajemen tersebut, maka para amilin di BAZNAS Kabupaten Bandung diikutkan pada program pelatihan dan program perencanaan SDM yang dilakukan oleh Pemkab Bandung bekerja sama dengan MUI kabupaten Bandung berserta Ormas Keagamaan (Islam) yang ada di Bandung. Program ini juga merupakan proses analisis dan identifikasi tersedianya kebutuhan akan sumber daya manusia amilin.

Kompetensi amilin menurut Islam adalah persyaratan amilin yang harus sesuai dengan sifat-sifat Rasulullah SAW yaitu shiddiq, fathonah, amanah dan tabligh (SIFAT) dan persyaratan administrif yang diatur dalam UU Nomor 23 Tahun 2011 Tentang Pengelolaan Zakat serta peraturan-peraturan lain yang berlaku di Indonesia. Kemudian tingkat kompetensi amilin dalam mengelola zakat infaq shadaqah di BAZNAS Kabupaten Bandung mengalami peningkatan seiring dengan program perencanaan SDM yang dilakukan melalui penyelenggaraan pelatihan bagi para amilin di BAZNAS Kabupaten Bandung. Kompetensi amilin dalam mengelola zakat infaq shadaqah di BAZNAS Kabupaten Bandung telah sesuai dengan persyaratan amilin yang harus sesuai dengan sifat-sifat Rasulullah SAW yaitu shiddiq, fathonah, amanah dan tabligh (SIFAT) dan persyaratan administrtif yang diatur dalam UU Nomor 23 Tahun 2011 Tentang Pengelolaan Zakat serta peraturan-peraturan lain yang berlaku di Indonesia.

Kompetensi amalin di BAZNAS Kabupaten Bandung dalam pengelolaan zakat, hal ini dapat memberikan paradigm baru bahwa pekerjaan sebagai amil zakat pun dapat dikategorikan sebagai profesi yang memiliki standar khusus. Sehingga tingkat profesionalisme amilin dalam melaksanakan tugas dan fungsinya dapat diukr secara kongkret dan memberikan peluang bagi para aktivis dakwah, akademisi dan penggiat zakat untuk menjadi seorang amil yang professional.

\section{KESIMPULAN}

1. Kompetensi Amilin menurut Islam adalah persyaratan amilin yang harus sesuai dengan sifatsifat Rasulullah SAW yaitu shiddiq, fathonah, amanah dan tabligh (SIFAT) dan persyaratan administrif yang diatur dalam UU Nomor 23 Tahun 2011 Tentang Pengelolaan Zakat serta peraturan-peraturan lain yang berlaku di Indonesia.

2. Tingkat kompetensi amilin dalam mengelola zakat infaq shadaqah di BAZNAS Kabupaten Bandung berdasarkan hasil penelitian mengalami peningkatan siring dengan program perencanaan SDM yang dilakukan melalui penyelenggaraan pelatihan bagi para amilin di BAZNAS Kabupaten Bandung.

3. Analisis kompetensi amilin dalam mengelola zakat infaq shadaqah di BAZNAS Kabupaten Bandung telah sesuai dengan persyaratan amilin yang harus sesuai dengan sifat-sifat Rasulullah SAW yaitu shiddiq, fathonah, amanah dan tabligh (SIFAT) dan persyaratan administrtif yang diatur dalam UU Nomor 23 Tahun 2011 Tentang Pengelolaan Zakat serta peraturan-peraturan lain yang berlaku di Indonesia

\section{DAFTAR PUSTAKA}

[1] A. Riawan Amin dan Tim PEBS FEUI, Menggagas Manajemen Syariah: Teori dan Praktik, Jakarta: Salemba Empat, 2010) hlm. 234.

[2] Depag RI, Al Quran dan terjemanahan, Jakarta : Pustaka Al Kautsar, 2010.

[3] Didin Hafidhuddin,Zakat Dalam Perekonomian Modern, Jakarta: Gema Insani, 2002.

[4] Fahruddin, Fiqh dan Manajemen Zakat Indonesia Cet-1, Malang: UIN Malang Press, 2008.

[5] Muhammad Ali, Kamus Lengkap Bahasa Indonesia Modern, Jakarta : Pustaka Amani, 2005.

[6] Muhammad Ismail Al bukhari, Shahih Bukhari Kitab Ilmu Hadits Nomor 57, (Terjemagan oleh Muhammad Nasruddin), Jakarta : Pustaka Azzam, 2009.

[7] Muhammad Ridwan, Manajemen Baitul Maal Wa Tamwil(BMT) Cet-2, Yogyakarta:UII Press, 2005. 